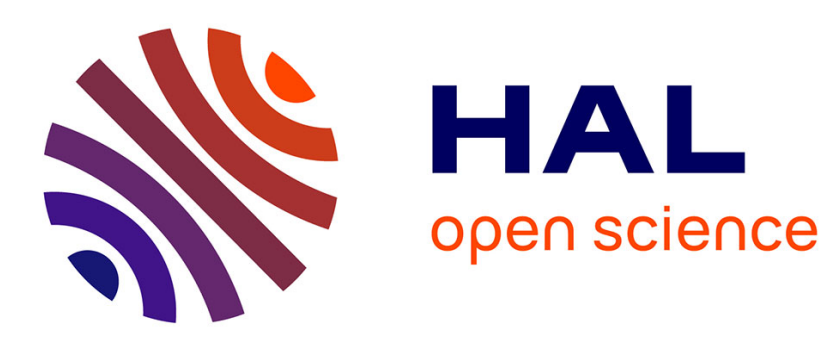

\title{
NUCLEATION AND GROWTH OF APERIODIC CRYSTALS IN ALUMINUM ALLOYS
}

\author{
R. Schaefer, L. Bendersky, F. Biancaniello
}

\section{To cite this version:}

R. Schaefer, L. Bendersky, F. Biancaniello. NUCLEATION AND GROWTH OF APERIODIC CRYSTALS IN ALUMINUM ALLOYS. Journal de Physique Colloques, 1986, 47 (C3), pp.C3-311-C3-320. 10.1051/jphyscol:1986332 . jpa-00225744

\section{HAL Id: jpa-00225744 https://hal.science/jpa-00225744}

Submitted on 1 Jan 1986

HAL is a multi-disciplinary open access archive for the deposit and dissemination of scientific research documents, whether they are published or not. The documents may come from teaching and research institutions in France or abroad, or from public or private research centers.
L'archive ouverte pluridisciplinaire HAL, est destinée au dépôt et à la diffusion de documents scientifiques de niveau recherche, publiés ou non, émanant des établissements d'enseignement et de recherche français ou étrangers, des laboratoires publics ou privés. 
NUCLEATION AND GROWTH OF APERIODIC CRYSTALS IN ALUMINUM ALLOYS

\author{
R.J. SCHAEFER, L.A. BENDERSKY and F.S. BIANCANIELLO \\ Metallurgy Division, National Bureau of Standards, \\ Gaithersburg, MD 20899, U.S.A.
}

\begin{abstract}
The icosahedral and decagonal aperiodic phases dominate the microstructures of rapidly solidified $A l-M n$ alloys because their nucleation and growth behavior differs substantialiy from that of the equilibrium phases. Electron beam surface melting can be used to produce a wide range of solidification conditions, in which the different stages of the nucleation and growth processes can be observed. It is found that the icosahedral phase nucleates abundantly in supercooled Al-Mn melts, and that the decagonal phase is subsequently nucleated by the icosahedral phase. Addition of Si to the Al-Mn alloys suppresses formation of the decagonal phase, but in these alloys the hexagonal $\beta$ phase can grow rapidly.
\end{abstract}

\title{
I - INTRODUCTION
}

In rapidiy solidified Al-Mn alloys, aperiodic crystals form by a nucleation and growth process and the individual crystals reach diameters of typically a few micrometers before their growth is stopped. Moreover, they are usually embedded in a matrix of f.c.c. Al, and frequently exist as mixtures of the icosahedral [1] and decagonal [2] phases. Although much has been learned from study of such materials, they are far from ideal for many measurements. Thus they may be quite suitable for certain TEM studies, somewhat less satisfactory for examination by $x$-ray and neutron diffraction and almost useless for other studies such as measurement of transport properties.

Looked at from a more positive viewpoint, however, studies of the microstructural details of these samples provide us with a great deal of information about the nucleation and growth behavior of the aperiodic phases. It is found that the nucleation behavior of the aperiodic phases is quite different from that of the equilibrium phases of the AT-Mn system, and this difference can account for the dominance of the aperiodic phases in rapidiy solidified alloys.

In this paper, the microstructures of rapidly solidified Al-Mn alloys will be interpreted in terms of conventional metal solidification processes such as nucleation and dendritic growth, and the implications with respect to crystalmelt interface properties and sample inhomogeneity will be discussed. Most of the conclusions will not depend on the fact that the phases in question have unusual crystal structures.

\section{II - COMPOSITION OF THE PHASES}

The first icosahedral crystals reported were observed in melt-spun ribbons of an alloy with overall composition close to that of $\mathrm{Al}_{6} \mathrm{Mn}, \mathrm{i.e.,} 14 \mathrm{at} \% \mathrm{Mn}$. At this composition, TEM shows that the icosahedral crystals have grown with a dendritic structure, characteristic of a solute redistribution process. The icosahedral crystals are embedded in f.c.c. Al which stands out strongly in x-ray diffraction patterns. These facts alone indicate that the icosahedral phase crystals hàve a Mn content greater than 14 at\%. 
In an attempt to eliminate the residual Al, a series of melt-spun samples was prepared with higher Mn contents [3]. X-ray diffraction indicated that the $A 1$ peaks disappeared when the Mn content reached slightly greater than 20 at $\%$. However, at about 16 at\% an additional phase, subsequently identified as decagonal, started to appear in the x-ray diffraction patterns. The amount of this phase was strongly dependent on the ribbon thickness, being greater in thicker ribbons. It was found that the thinnest parts of 20 at\% Mn ribbons were almost single phase icosahedral but the thicker parts of ribbons with the same composition were approximately half icosahedral and half decagonal phase. The composition of the icosahedral phase was thus concluded to be approximately $20 \mathrm{at} \% \mathrm{Mn}$, but the production of single phase material required the highest possible cooling rates to avoid formation of the decagonal phase. Other authors $[4,5,6]$ have reached a similar conclusion with respect to the composition of the icosahedral phase. Ribbons of 21 to 22 at\% Mn were single phase decagonal except in their thinnest parts where some icosahedral phase was still present. One might note that none of the Al-rich intermetallic phases of the Al-Mn equilibrium system can be formed as single phase materials by either slow or rapid cooling an alloy having the composition of the desired phase: they all form by peritectic reactions and the equilibrium distribution of phases would be expected only after long anneals.

Measurements of the position of the strongest $x$-ray diffraction peak from the icosahedral phase showed that as the overall alloy composition changed from 8 to 26 at\% Mn, the spacing of the planes responsible for this peak decreased by approximately $1 \%$. This change indicates that the icosahedral phase is not a "line compound" with a fixed composition, but forms with a range of compositions. Not only does this imply that in alloys of differing initial compositions the icosahedral crystals will have different average compositions, it also implies that by the normal processes of alloy solidification a range of compositions will occur in different parts of an individual icosahedral crystal [7]. Although the $x$-ray data by themselves are not sufficient to accurately determine what the range of composition of the icosahedral phase is, they clearly show that caution must be used in assigning any fixed composition or lattice parameter to the icosahedral phase.

Although a composition (20 at\%. Mn) was thus identified at which almost singlephase icosahedral material can be formed, the solidification rates required to avoid formation of the decagonal phase at this composition were difficult to obtain for large amounts of material. It was therefore attempted to stabilize the icosahedral phase by replacing a fraction of the Al atoms with smaller atoms, thereby slightly reducing the average size of the atoms at the Al sites. Addition of $\mathrm{Si}$ to the alloy was found to be effective, with an alloy containing 20 at\% $\mathrm{Mn}$ and 6 at\% Si being single phase icosahedral with no formation of decagonal phase. Other authors [8] have found the same result and have attributed the easy icosahedral phase formation at this composition to the similarity in structure of the icosahedral phase to the cubic ternary $\alpha$ phase of Al-Mn-Si. There is nothing contradictory about the two explanations for the beneficial effects of adding Si.

\section{II - NUCLEATION OF ICOSAHEDRAL PHASE}

To obtain more detailed information on the conditions under which the aperiodic phases form, a series of electron beam surface melting experiments was carried out. In this work, a $25 \mathrm{kV}$ electron beam, focussed to a diameter. of approximately $1 \mathrm{~mm}$, is scanned across the surface of a bulk alloy sample at velocities ranging from 0.1 to $500 \mathrm{~cm} / \mathrm{sec}$. A moving melt zone is thus created, and the microstructures of the resolidified material are examined by x-ray diffraction, and optical and electron microscopy. Such experiments have been carried out in alloys containing $1.5,3.6,4.6,7.4,9.7,12.2,14.1$, and 17.4 at\% $\mathrm{Mn}$. At low scan rates, dendrites or plates of the equilibrium phases propagate from the substrate into the melt zone. Above a critical velocity, which increases with increasing $\mathrm{Mn}$ content, the intermetalijic phases cannot propagate fast enough to keep up with the melt zone. In alloys containing $\leqslant 7.4$ at $\% \mathrm{Mn}, \mathrm{Al}_{6} \mathrm{Mn}$ dendrites are replaced by a 
eutectic between $\mathrm{Al}_{6} \mathrm{Mn}$ and $\mathrm{Al}$, and then at slightly higher velocity by cellular aluminum. In the alloys containing $\geqslant 9.7 \mathrm{at} \% \mathrm{Mn}$, the growth of the equilibrium intermetaliics stops when the aperiodic phases nculeate ahead of them in the melt zone. The effect is seen clearly in the 9.7 at\% Mn alloy, where the icosahedral crystals are easily recogized by their pentagonal shape (discussed below). Fig. 1 shows an example of how the progress of a family of $\mathrm{Al}_{6} \mathrm{Mn}$ dendrites has been blocked by icosahedral crystals nucleated in the melt, in an electron beam melt scanned at $2.5 \mathrm{~cm} / \mathrm{sec}$.

Using an extension of an earlier analysis by Eady et al. [9] of the growth kinetics of $\mathrm{Al}_{6} \mathrm{Mn}$ dendrites, we can estimate [3] that the tips of the dendrites shown in Fig. 1 were at a temperature about $16^{\circ} \mathrm{C}$ below the equilibrium eutectic temperature of $658^{\circ} \mathrm{C}$. The icosahedral grains nucleated ahead of the dendrites, where the temperature must have been slightly higher. The equilibrium liquidus temperature at this composition is about $850^{\circ} \mathrm{C}$, so it is clear that a rather high supercooling $\left(150-200^{\circ} \mathrm{C}\right)$ is required to produce the icosahedral phase nucleation. Once this supercooling is reached, however, large numbers of. icosahedral crystals nucleate in the melt. From observation of the size attained by the icosahedral crystals following nucleation, it was estimated that at this composition the icosahedral crystals grew with velocities between 1 and $2.5 \mathrm{~cm} / \mathrm{sec}$, at their nucleation temperature. Their ability to replace the equilibrium phases is thus due not to a particularly high growth rate, but to a high nucleation rate in the undercooled liquid.

The high nucleation rate of the icosahedral crystals within the supercooled melt, and its rather sudden onset when a specific level of supercooling is reached, suggest that the nucleation of this phase may be homogeneous, j.e., not catalyzed by a substrate of some solid impurity microparticles within the melt. The experiments of Bendersky and Ridder [10], in which extremely high rates of icosahedral phase nucleation were seen in rapidly cooled submicron droplets of Al-Mn, provide further support for homogeneous nucleation of the icosahedral phase. This is in contrast to the behavior of the equilibrium phases, which nucleate only on a few heterogeneous sites. At slow cooling rates, the equilibrium phases can then grow throughout the entire sample and prevent formation of the icosahedral phase, whereas at high cooling rates the equilibrium phases do not become large enough to be detected before the onset of rapid nucleation of the icosahedral phase.

IV - GROWTH FORM OF THE ICOSAHEDRAL PHASE

Although in most melt-spun ribbons icosahedral crystals do not have an external shape which reveals the symmetry of their structure, in the alloys containing 9.7 at: Mn the electron beam melting experiments produced crystals with dramatic icosahedral symmetry in their external shape (Fig. 2). The crystals grow from their point of nucleation as dendrites which propagate along their three-fold axes, with side branches from each main stem growing in the direction of adjacent three-fold axes. The resulting figure is a hollow-faced pentagonal dodecahedron. How is the preferred dendrite growth direction selected? Dendritic growth has been the subject of much theoretical analysis recently [11], but many details of the process are still poorly understood. Dendrite growth occurs under conditions where diffusion of heat and/or solute are limiting factors in the rate of crystal growth. Diffusion in the liquid and in the icosahedral phase must be isotropic and thus cannot contribute to selecting the dendrite growth direction. However, the properties of the solid-liquid interface, specifically the solid-liquid surface energy and the kinetic function relating the growth rate of the crystal to the local temperature and composition at the interface, can be anisotropic and can account for the growth direction.

When cubic materials grow dendritically, they almost invariably grow along the cube axes. The diffusional effects which drive dendritic growth can transform a slight anisotropy of surface energy or kinetics into a strong anisotropy of growth direction. For example, in dendritic growth of the b.c.c. organic material succinonitrile into 


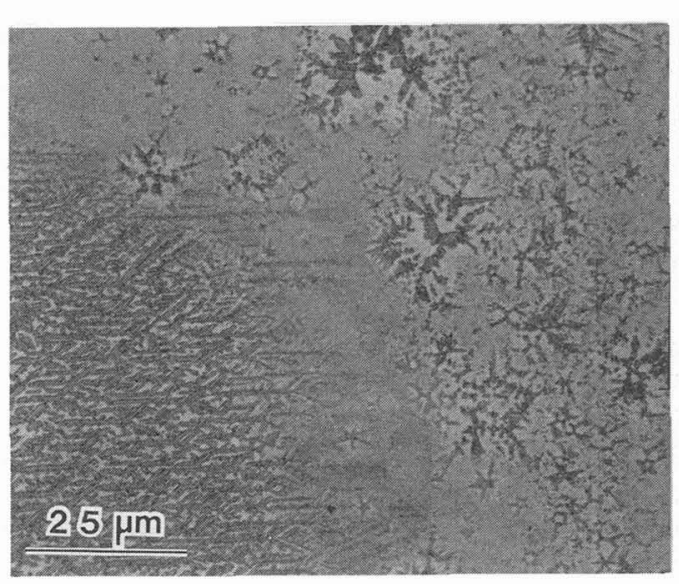

Fig. 1. Icosahedral crystals nucleated ahead of advancing $\mathrm{Al}_{6} \mathrm{Mn}$ dendrites in an A1-9.7 at\% Mn alloy

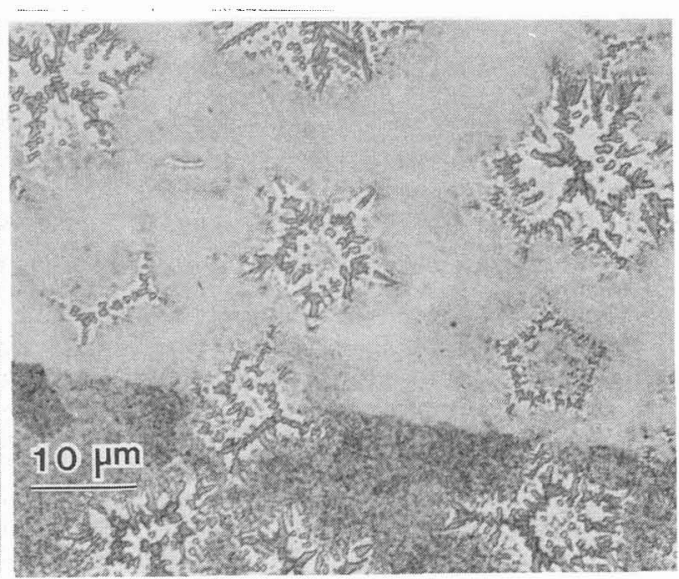

Fig. 2. Icosahedral dendrites in an Al-9.7 at\% Mn alloy.

a pure supercooled melt, the growth direction is believed to be controlled by anisotropy of surface energy, with interfacial kinetic effects being relatively unimportant. Although the surface energy anisotropy is measured to be only about $2 \%$ [12], the dendrites grow with a: strong preference for the [100] directions. The solid-liquid surface energy is greatest on the planes normal to the cube axes with the result that a small crystal in equilibrium with the melt would have the shape of a sphere with slight bulges in the directions of the cube axes. These slight bulges are sufficient, however, to give the cube axis directions an advantage in the diffusional growth process, with the result that the bulges become progressively further developed and grow outward as the tips of dendrites. Fig. 3 shows such a crystal starting to develop into a dendrite with [100] branches. Note that no crystallographic facets are present on the crystal.

When interfacial kinetics play an important role in the crystallization process, the growth form frequently becomes bounded by facets of the slowly growing planes, which in the case of most f.c.c. metals are the $\{111\}$ planes. Such facets may be seen in cases where the composition differs greatly from that of the melt, or in electrolytically formed dendrites. Crystals with complex crystal structures are almost always facetted. Fig. 4 shows a crystal of white phosphorus ( $P_{4}$, complex cubic $\alpha$-Mn structure) which had a rounded form when equilibrated for several hours with its melt at the equilibrium temperature, but developed $\{110\}$ facets when growth was started by lowering the temperature 8 millidegrees. The $\{110\}$ facets of the $\dot{P}_{4}$ crystal lead to sharp points in the [100] directions, and at higher supercooling [100] dendrites are formed. For $\{111\}$ facets, the crysta] assumes an octahedral morphology and the dendrites grow from the points of the octahedron, in the [100] directions.

The observation that icosahedral crystals grow along the three-fold axes can thus imply an anisotropy of either surface energy or interfacial kinetics. Either of these mechanisms would be consistent with the idea that planes normal to the fivefold axes of the icosahedral phase are the most densely packed: these planes would then have the lowest surface energy and would also be the most difficult planes on which to start new layers of crystal.

While dendrite growth can result from diffusion of either heat or solute, the latter must have been the dominant effect for the dendrites shown in Fig. 2 . A region depleted in $M_{n}$ can be seen surrounding the icosahedral dendrites but 


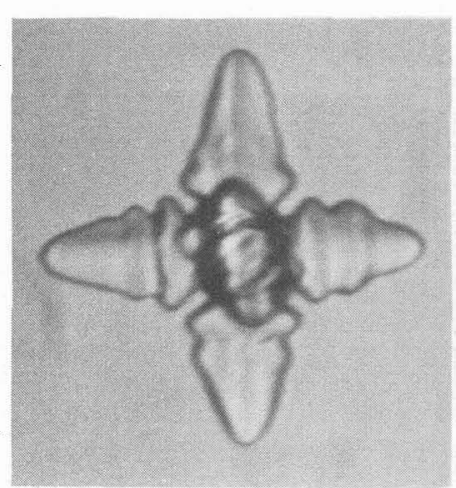

Fig. 3. Dendrite of succinonitrile.

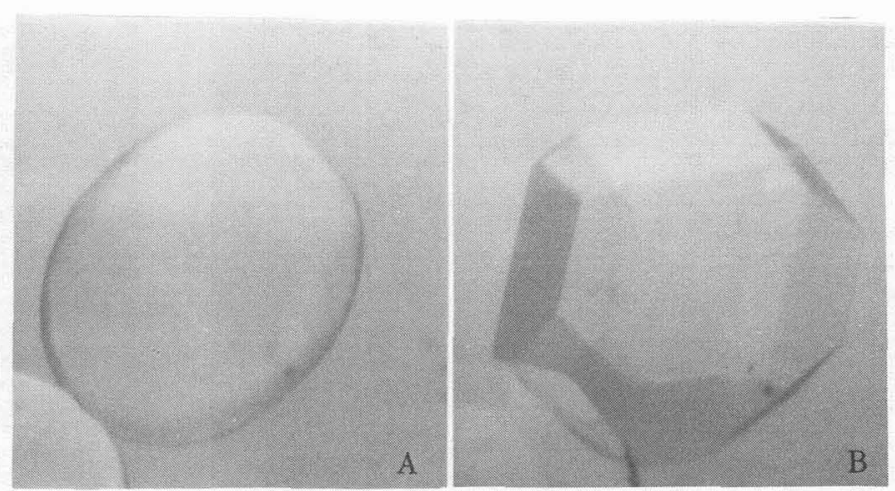

Fig. 4. A crystal of white phosphorus (a) at equilibrium with its melt and (b) growing at a supercooling of $0.008 \mathrm{~K}$.

extending only about a micrometer from the dendrites, which grew to a radius of about $10 \mu \mathrm{m}$ in about $1 \mathrm{msec}$. Estimating diffusion distances as $x \approx \sqrt[V]{D t}$, where $t$ is the time and $D$ is thermal or solute diffusivity, we obtain for $1 \mathrm{msec}$ about $300 \mu \mathrm{m}$ for thermal diffusion $\left(D \approx 1 \mathrm{~cm}^{2} / \mathrm{sec}\right)$ and $1 \mu \mathrm{m}$ for solute diffusion $\left(D \approx 10^{-5} \mathrm{~cm}^{2} / \mathrm{sec}\right)$. The latter is comparable to the size of the dendrite arms, whereas the former is more than an order of magnitude larger than the entire dendritic crystal, indicating that the thermal field must have been almost uniform within an individual crystal.

\section{$V$ - NUCLEATION OF DECAGONAL PHASE}

The decagonal phase is favored in alloys having a higher Mn content and a lower solidification rate. Many alloys contain both phases and in these cases it is found that the decagonal phase has grown as an oriented overgrowth on the icosahedral phase, with the ten-fold axis of the decagonal phase coinciding with one of the five-fold axes of the icosahedral phase [13]. Thus each icosahedral phase crystal generates six different orientations of decagonal crystals, one for each of the five-fold axes.

In electron beam surface melts of Al-14 at\% Mn alloys, $100 \mathrm{~cm} / \mathrm{sec}$ scans were found to contain icosahedral crystals with morphologies similar to those found in the 18 wt\% Mn alloys, but the structure is filled in with a higher volume fraction of the icosahedral phase. Scans at $25 \mathrm{~cm} / \mathrm{sec}$ show a mixture of icosahedral and decagonal, while scans at $10 \mathrm{~cm} / \mathrm{sec}$ or less show only the decagonal phase or (in other parts of the melt) $\mathrm{Al}_{6} \mathrm{Mn}$.

The decagonal phase regions in the slower melts show a distinctive morphology. Individual decagonal crystals have the form of blocky cylinders, $1-2 \mu \mathrm{m}$ long and about $1 \mu \mathrm{m}$ in diameter (Fig. 5). Although these crystals do not in general appear to be connected to one another, many of them are arranged in long rows which at low magnification give the impression of a dendritic structure. The symmetry of this dendritic structure suggests icosahedral dendrites such as those shown in Fig. 2. Moreover, within any one such dendrite-like colony, the decagonal crystals have a limited number of orientations, namely those which would result if they had all been nucleated by an individual icosahedral crystal.

This morphology indicates that the decagonal crystals in the slower melts did not result from homogeneous nucleation events, but that they formed by heterogeneous epitaxial nucleation on large icosahedral crystals. The latter, however, have completely disappeared by the time solidification is complete, having been replaced by the more stable decagonal phase. It is still possible, however, to find 


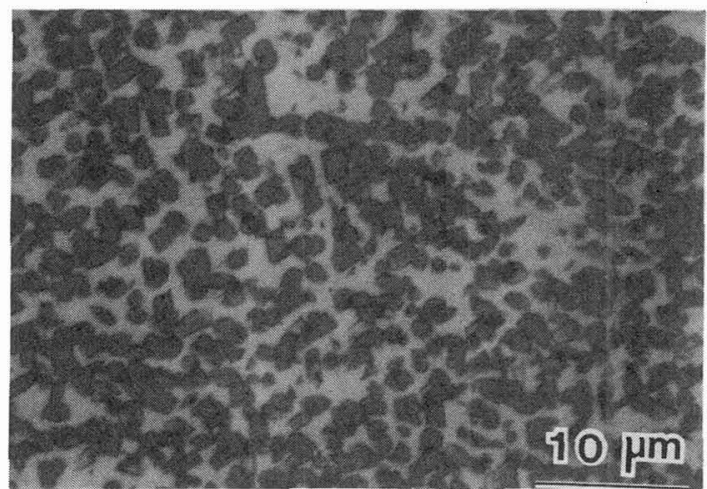

Fig. 5. Decagonal crystals in an

A] -14 at\% Mn alloy scanned at $2.5 \mathrm{~cm} / \mathrm{sec}$.

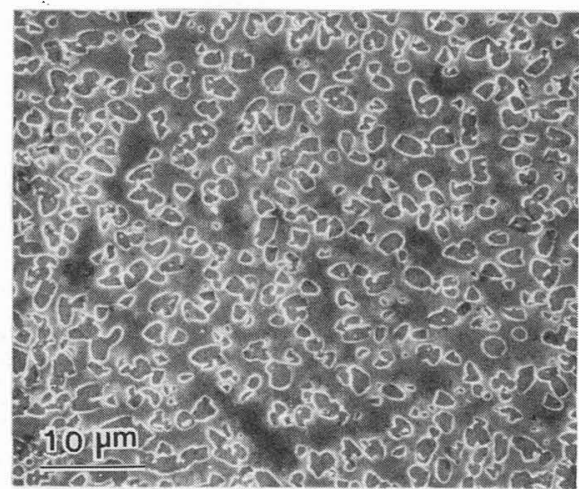

Fig. 6. Remnant of an icosahedral structure among decagonal crystals, from the same sample as Fig. 5 .

regions where the icosahedral crystals have left a "ghost" image, probably due to locally higher Mn content in the Al matrix (Fig. 6).

The processes found in these alloys render it extremely difficult to grow large crystals of the icosahedral phase in binary Al-Mn alloys. The icosahedral phase serves as a highly effective nucleant for the more stable decagonal phase, and formation of the decagonal phase can be suppressed only by very rapid cooling following growth of the icosahedral phase. This rapid cooling, however, results in a high rate of nucleation of the icosahedral phase, with subsequent small grain size.

The order of magnitude of the cooling rates required to suppress formation of the decagonal phase in the Al-14 at\% Mn alloy can be estimated from the electron beam melting experiments. Numerical models [14] of surface melting by a moving heat source show that so long as the parameter $\mathrm{Ua} / 2 \alpha$ is $\leqslant 1$, the shape of the melt pool is not greatly distorted from the shape of a stationary melt. Here $U$ is the velocity, a the radius of the heat source, and $\alpha$ the thermal diffusivity. In this case $a \approx 5 \times 10^{-2} \mathrm{~cm}$ and $\alpha \approx 1 \mathrm{~cm}^{2} / \mathrm{sec}$, and the melt pool distortion is small for $U \leqslant 40 \mathrm{~cm} / \mathrm{sec}$. Observation of ripples left behind on the sample surface also indicate that in melts of this velocity the melt pool remains fairly round, while at higher speeds $(200$ or $500 \mathrm{~cm} / \mathrm{sec}$ ) the trailing edge of the melt pool becomes pointed.

For melts in the slower velocity range, the temperature gradient at the solid-liquid interface is thus similar to that in a stationary melt, which is $\left(T_{m}-T_{0}\right) / R$, in the case where all of the heat is concentrated at one point and only slightly smaller when the heat is uniformly distributed over the surface of the melt. Here $T_{m}$ is the melting temperature, $T_{0}$ is the substrate temperature far from the melt, and $R$ is the radius of the melt. In the present case the gradient at the solid liquid interface is thus approximately $10^{4} \mathrm{~K} / \mathrm{cm}$, and the cooling rate is equal to the gradient at the interface times the electron beam scan velocity. In the $10 \mathrm{~cm} / \mathrm{sec}$ scans, this gives $10^{5} \mathrm{k} / \mathrm{sec}$, and at this cooling rate the icosahedral phase was totally transformed into decagonal phase.. For $100 \mathrm{~cm} / \mathrm{sec}$ scans the same calculation would give $10^{6} \mathrm{k} / \mathrm{sec}$, but due to melt pool distortion at this scan speed the actual cooling rate was probably somewhat smaller. At this scan speed, the icosahedral crystals are preserved. We can thus conclude that for the $14 \mathrm{at} \% \mathrm{Mn}$ alloy the critical cooling rate needed following nucleation to prevent transformation of the icosahedral crystals into the decagonal phase is between $10^{5}$ and $10^{6} \mathrm{~K} / \mathrm{sec}$. 


\section{VI - ALLOYS CONTAINING SILICON}

The addition of $\mathrm{Si}$ to $\mathrm{Al}-\mathrm{Mn}$ alloys eliminates the formation of the decagonal phase and thus makes it possible to obtain single-phase icosahedral material in melt-spun ribbons of Al-20 at\% Mn-6 at\% Si. Chen and Chen [15] have discussed differences between the electron diffraction patterns of alloys with and without $\mathrm{Si}$, but the difference in structure is apparently subtle and the x-ray diffraction patterns are very similar.

Electron beam surface melting of alloys containing $S i$ demonstrated that the hexagonal $\beta$ phase of Al-Mn-Si grows rapidly so that high scan rates were necessary to eliminate it. Table I shows the phases detected by $x$-ray diffraction in electron beam melts of three silicon-containing alloys. It is seen that the $\beta$ phase persists to relatively high velocities and the $\alpha$ phase to even higher velocities. Metallographic examination shows a microstructure (Fig. 7) containing plates which are identified as the $\beta$ phase on the basis of their reaction to polarized light. In the regions between the $\beta$ plates is a granular structure which does not react to polarized light and which is identified as a mixture of icosahedral and the cubic $\alpha$ phase. Koskenmaki et al. [16] have demonstrated that in these alloys the $\alpha$ phase forms as an oriented overgrowth on the icosahedral phase, somewhat similar to the overgrowth of decagonal phase on icosahedral in binary Al-Mn alloys. The nucleation and growth of the $\alpha$ phase on the icosahedrat phase

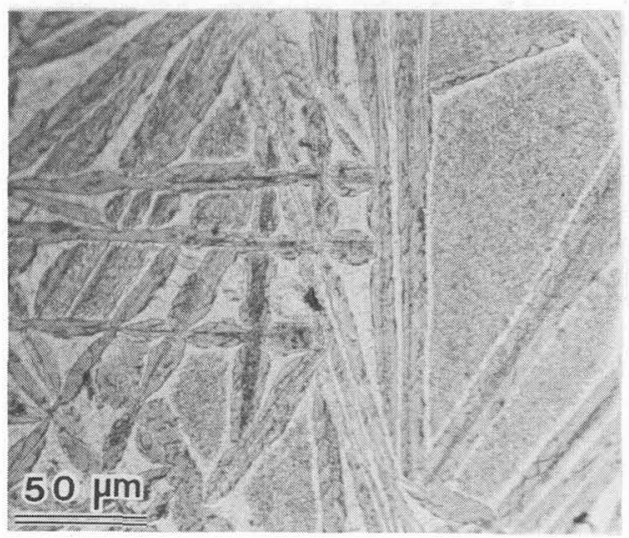

Fig. 7. Microstructure of Al-15 at\% Mn-6 at\% Si alloy scanned at $5 \mathrm{~cm} / \mathrm{sec}$.

\section{TABLE I}

Intermetallic phases present in alloys with 6 at\% Si. The dominant phase is listed first.

\begin{tabular}{cccc} 
& \multicolumn{3}{c}{ Mn Content (at \%) } \\
\cline { 2 - 4 } $\begin{array}{c}\text { Scan Velocity } \\
(\mathrm{cm} / \mathrm{sec})\end{array}$ & 10 & 15.5 & 20 \\
\hline 500 & $\mathrm{I}$ & & \\
200 & $\mathrm{I}+\alpha$ & $\mathrm{I}+\boldsymbol{\beta}$ & $I+\beta$ \\
100 & $\alpha+\mathrm{I}$ & $\mathrm{I}+\boldsymbol{\beta}$ & $\beta$ \\
50 & $\alpha$ & $\beta$ & $\beta$ \\
25 & & $\beta$ & $\beta$ \\
10 & $\alpha+\beta$ & $\beta+\alpha$ & $\beta$ \\
5 & $\beta+\alpha$ & $\beta+\alpha$ & $\beta$ \\
2.5 & & \\
\hline
\end{tabular}


in $\mathrm{Al}-\mathrm{Mn}-\mathrm{Si}$ is apparently not so rapid as the nucleation and growth of the decagona? phase on icosahedral in Al-Mn, making it easier to obtain single-phase icosahedral material in the former system.

\section{VII - DECAGONAL PHASE NUCLEATION AND GROWTH IN AI-Pd ALLOYS}

There have been no reports of icosahedral phase formation in the Al-Pd system, but Bancel et al. [17] have found that the decagonal phase is present. Earlier studies by Sastry et a1. [18] indicated that this phase formed by precipitation, and the data suggest that the decagonal phase may be an equilibrium phase in this system. We have found that in melt-spun ribbons of $\mathrm{Al}-14 \mathrm{at} \% \mathrm{Pd}$ dendrites of the decagonal phase are formed, followed by a eutectic between the decagonal phase and aluminum (Fig. 8). In electron beam melt trails, examination of the sample surface reveals dendritic crystals with ten-fold branching (Fig. 9). In neither melt spun ribbons nor electron beam melts was any indication seen of decagonal crystals which had multiple orientations due to epitaxial nuclation on an underlying icosahedral crystal. It is therefore concluded that the decagonal phase crystals which we observed in Al-Pd were not nucleated by an icosahedral precursor, but there is not yet enough evidence to indicate whether the nucleation was homogeneous.
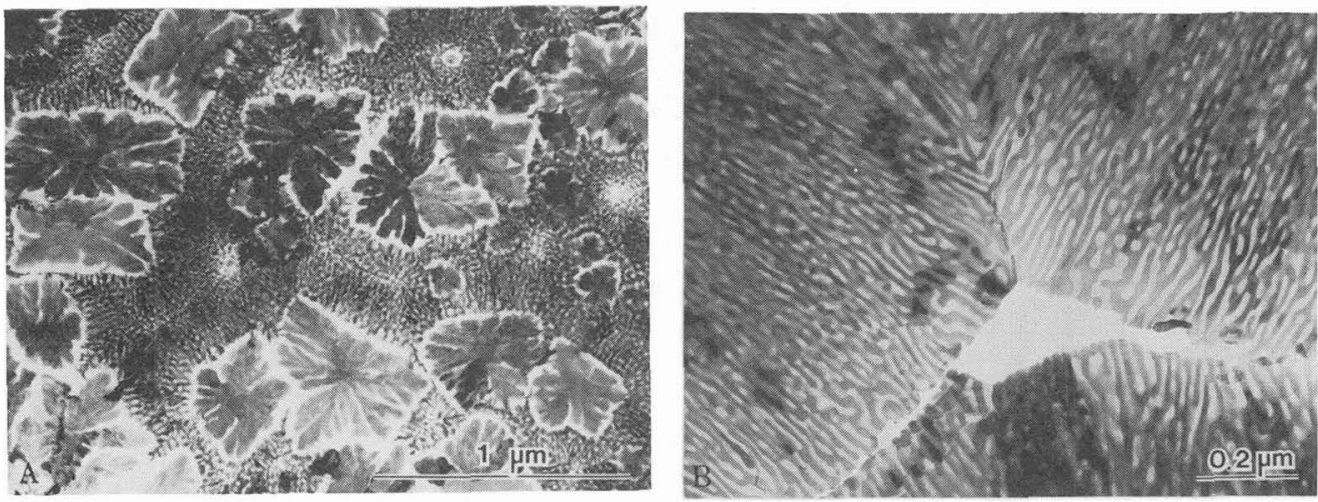

Fig. 8 Decagonal crystals in a melt-spun AT-Pd alloy, showing (a) dendrites surrounded by eutectic and (b) detail of eutectic structure.

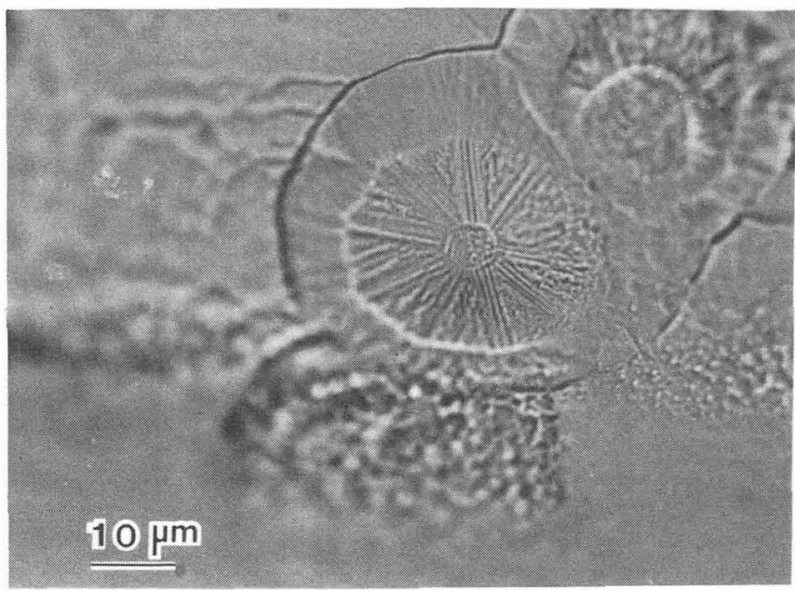

Fig. 9 Decagonal dendrite in an electron beam melted AT-14 at $\%$ Pd alloy. 
VII - CONCLUSIONS

(1) The icosahedral phase solidifies from the melt of binary Al-Mn alloys with a composition close to $20 \mathrm{at} \% \mathrm{Mn}$, but it is not a line compound.

(2) A supercooling of $150-200^{\circ}$ below the equilibrium liquidus temperature is required to produce nucleation of the icosahedral phase: the resulting nucleation rate is extremely high, suggesting homogeneous nucleation.

(3) The decagonal phase is nucleated heterogeneously on the surface of the icosahedral phase.

(4) At a cooling rate of $10^{5} \mathrm{k} / \mathrm{sec}$ or less, the decagonal phase replaces the icosahedral phase, whereas at a cooling rate of $10^{6} \mathrm{~K} / \mathrm{sec}$ or more the icosahedral phase is preserved.

(5) The addition of $5 \%$ Si to Al-Mn alloys prevents the formation of the decagonal phase, but the ternary $\beta$ phase can grow rapidly in such alloys.

(6) In Al-Pd alloys, a decagonal phase nucleates and grows without an icosahedral phase precursor.

\section{VIII - ACKNOWLEDGEMENTS}

The authors thank OARPA for financial support of this work.

\section{REFERENCES}

1. Shechtman, D., Blech, I., Gratias, D., and Cahn, J. W., Phys, Rev. Lett. $\underline{53}$ (1984) 1951.

2. Bendersky, L., Phys. Rev. Lett. 55 (1985) 1461.

3. Schaefer, R. J., to be published in Scripta Met.

4. Guyot, P. and Audier, M., Phil. Mag. B 52 (1985) L15.

5. Krishnan, K. M., Gronsky, R., and Tanner, L. E., Scripta Met. 20 (1986) 239.

6. Kimura, K., Hashimoto, T., Suzuki, K., Nagayama, K., Ino, H., and Takeuchi, S., J. Phys. Soc. Japan 54 (1985) 3217.

7. Bower, T. F., Brody, H. D., and Flemings, M. C., Trans. AIME 236 (1966) 624.

8. Henley, C. L., J. Non-Cryst. Solids 75 (1985) 91.

9. Eady, J. A., Hogan, L. M., and Davies, P. G., J. Aust. Inst. Met. 20 (1975) 23.

10. Bendersky, L. A., and Ridder, S. D., to be published in Scripta Met.

11. Langer, J. S., Rev. Mod. Phys. 52 (1980) 1 .

12. Jones, D. R. H., and Chadwick, G. A., Phi T. Mag. 22 (1970) 291.

13. Schaefer, R. J., and Bendersky, L. A., to be published in Scripta Met.

14. Kou, S., Hsu, S. C., and Mehrabian, R., Met. Trans. 12B (1981) 33.

15. Chen, C. H., and Chen, H. S., Phys. Rev. B $33(1986)^{\frac{12}{28} 14 .}$

16. Koskenmaki, D. C., Chen, H. S., and Rao, K. V., Phys. Rev. B, to be published.

17. Bancel, P. A., Heiney, P. A., Stephens, P. W., Goldman, A. I., and Horn, P. M., Phys. Rev. Lett. 54 (1985) 2422.

18. Sastry, G. V. S., Suryanarayana, C., VanSande, M., and Van Tendeloo, G., Mat. Res. Bul1. 13 (1978) 1065.

\section{COMMENTS AFTER THE SCHAEFER TALK :}

J. ZAK.- Your slides show beautiful pentagonal shape structures in the icosahedral phase. I didn't seem to see any clear decagons in the decagonal phases. Do they at all appear? 
Response by R. SCHAEFER :

The decagonal phase of Al-Mn grows in the form of blocky cylinders which sometimes show a slight indication of 10-fold faceting. However, we have not seen them with a dendritic growth form, and the dentritic form greatly emphasises crystal symmetry because the dentrites graw in specific crystallographic directions. Preliminary experiments with Al-Pd, which solidifies with a decagonal structure, show some dendrites with branches having decagonal symmetry.

\section{DIVINCENZO.-}

1. Is there an epitaxial relationship between I-AlMn and e.g., orthorhombic $\mathrm{Al}_{6} \mathrm{Mn}$ ?

2. Is the e-beam power a useful control parameter ?

Response by $R$. SCHAEFER

1. None has been identified

2. The beam power can be used to vary the depth and shape of the melt zone within a limited range, but it is best to adjust the power to give a good melt and vary the scan rate. Somewhat higher powers are required to give an equivalent melt at high scan rates. 